\title{
An enhancement of the current design concepts for the improved consideration of residual stresses in fatigue-loaded welds
}

\author{
Th. Nitschke-Pagel ${ }^{1}$ (D) $\cdot$ J. Hensel ${ }^{1}$ \\ Received: 16 December 2019 / Accepted: 4 January 2021 / Published online: 11 February 2021 \\ (C) The Author(s) 2021
}

\begin{abstract}
The consideration of residual stresses in fatigue-loaded welds is currently done only qualitatively without reliable knowledge about their real distribution, amount and prefix. Therefore, the tools which enable a more or less unsafe consideration in design concepts are mainly based on unsafe experiences and doubtful assumptions. Since the use of explicitly determined residual stresses outside the welding community is state of the art, the target of the presented paper is to show a practicable way for an enhanced consideration of residual stresses in the current design tools. This is not only limited on residual stresses induced by welding, but also on post-weld treatment processes like HFMI or shot peening. Results of extended experiments with longitudinal fillet welds and butt welds of low and high strength steels evidently show that an improved use of residual stresses in fatigue strength approximation enables a better evaluation of peening processes as well as of material adjusted welding procedures or post-weld stress relief treatments. The concept shows that it is generally possible to overcome the existing extremely conservative but although unsafe rules and regulations and may also enable the improved use of high strength steels.
\end{abstract}

Keywords Residual stresses $\cdot$ Effective mean stress $\cdot$ Fatigue strength $\cdot$ High strength steel

\section{Introduction}

In the current design rules such as BS 7608, EC3, EN 13001, FKM guideline and finally IIW recommendations for fatigue design [2-6], residual stresses in welds are treated more or less consistently. The fundamental assumptions can be summarized as the following:

1. Residual stresses caused by welding and thermal cutting in sufficiently large welded components (not explicitly defined) are generally postulated to be tensile.

2. In cases where no stress-relief treatment is applied or no explicit knowledge about the real amount of the tensile residual stresses is available - perhaps by means of measurements or calculations - the residual stresses are

Recommended for publication by Commission XIII - Fatigue of Welded Components and Structures

Th. Nitschke-Pagel

t.pagel@tu-braunschweig.de

1 Institut für Füge- und Schweißtechnik, Technische Universität Braunschweig, Braunschweig, Germany supposed to reach the yield strength of the related base material.

3. The effect of residual stresses is equivalent to that of the mean stresses. This leads to a mean stress independency of the design values (FAT-classes), which are defined for a stress ratio of $R=0.5$.

4. Fatigue behaviour as described is generally uniformly valid and independent from the material (i.e. different steel grades, aluminium).

5. Often, the residual stress magnitude in relation to the yield limit is used as a reference for residual stress effects.

The described state of the art is initially founded on the works of [7, 8], Fig. 1. Here, data from some simple experiments with "small-sized" samples [7] and also large bridge girders [8] with different weld details produced of different steel grades have been analysed. In fact, the analysis was performed without any precise knowledge about the existing residual stresses. Nevertheless, the most detected results like the independency of the fatigue strength from the applied stress ratio were related to the assumed residual stresses. The consequence was a conservative approach, as mentioned above, assuming a generally existing upper stress close to the yield strength, being the sum of the resulting tensile 


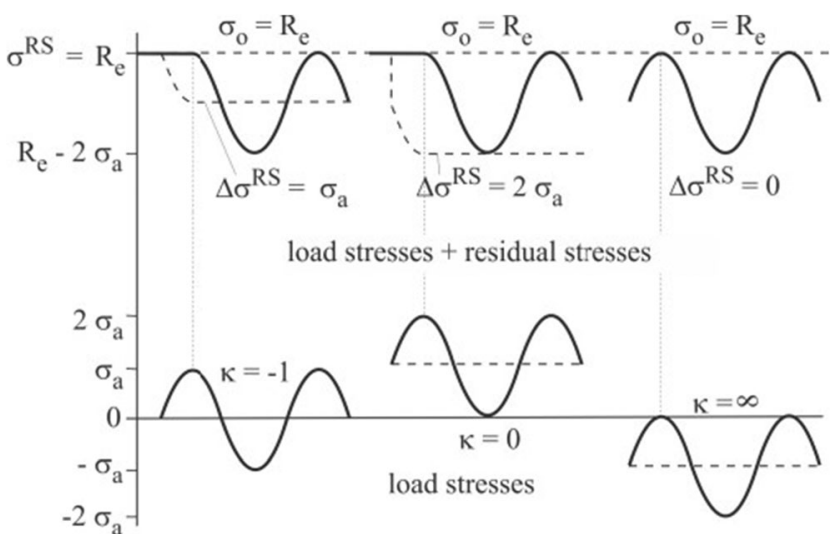

Fig. 1 Schematic illustration of the combined effect of load stresses and residual stresses (constant upper stress concept) [7]

residual stresses, mean stresses and stress amplitude. In [9], an improved version was used (Fig. 2), considering different initial residual stress amounts and distinguishing the different conditions as "high RS", "moderate RS" and "low RS". Here, "high" means as high as the yield strength of the base material and "low" an RS magnitude $\leq 0.2 \cdot R_{e}$. Haibach's idea was finally used for the FAT-class-related bonus factor concept from [9], which is established in the current design rules (Fig. 3) [1]. These investigations were conducted using ferritic-bainitic construction steels $\left(R_{e}<400 \mathrm{MPa}\right)$, whereby the findings were not transferred to high strength steels as commonly used in welded structures nowadays. The main intention of the recommended modus operandi in the current design rules is to provide a design tool that can be applied by engineers under practical boundary conditions. This means that several uncertainties in welding production, such as varying weld quality, rough environment, or even not always detailed knowledge about the local material properties, notch geometry and residual stress condition must be covered by relatively conservative design values (i.e. FAT-classes). On the other hand, improved quality standards in welding practice, which enable the consideration of detailed knowledge of

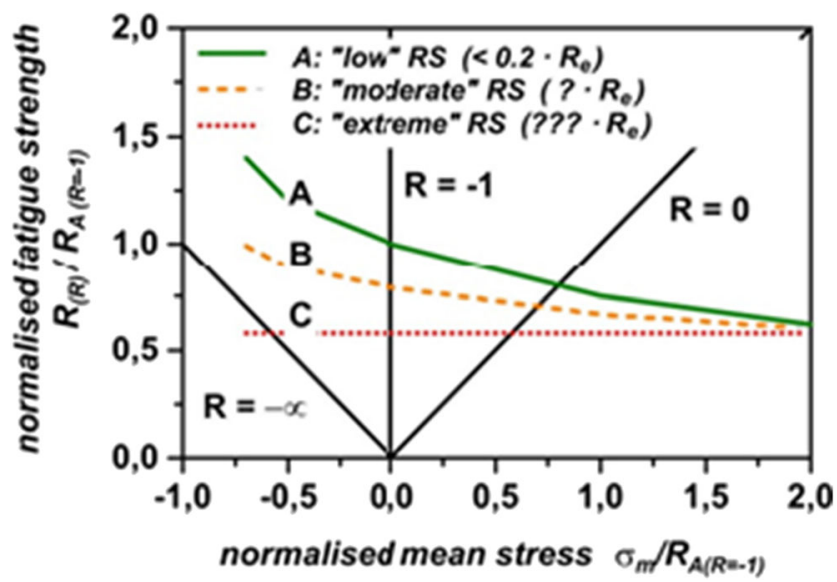

Fig. 2 Mean stress dependency due to different residual stress magnitudes [9]

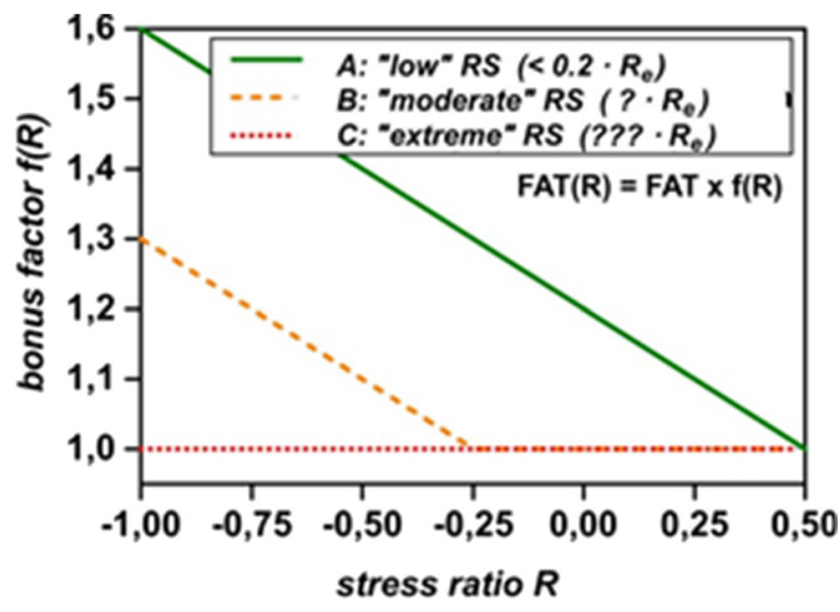

Fig. 3 Residual stress depending bonus factor concept due to IIW [1]

fatigue strength affecting parameters like material properties, notch stresses and residual stresses, should provide sophisticated fatigue design and finally the increased use of high strength steels.

The improved consideration of residual stresses in fatigue design is one conceivable additional tool which seems to be particularly helpful with regard to the increased use of high strength steels $[10,11]$, where a higher effectiveness of the residual stresses can be expected than with low strength materials. Unfortunately, there are really only a few investigations published in which residual stresses resulting from welding have been systematically observed. Some previous publications [12-16] tried to use measured residual stresses, but the published database is not suitable for an explicit design consideration because the residual stresses where not measured at the critical sites, the relaxation behaviour was not observed or no significant residual stresses where found in the observed welds. On the other hand, mostly mild steels were investigated [17] and no explicit effect of the residual stresses was found. Newer investigations (overview in [11]) were mainly dealing with compressive residual stresses introduced by mechanical post-weld treatments. Here, the residual stresses were qualitatively used for the implementation in design recommendations without explicit consideration of the amount of the residual stresses [18, 19].

A detailed view on the practice of handling residual stresses in the current design rules reveals the main limitations for such an approach, which are finally based on some fundamental errors, misinterpretations and also disregarding technical developments.

- The applied equalization of residual stresses and mean stresses is not reasonable due to their different nature. While mean stresses are commonly a constant load, residual stresses are locally effective and may vary during the 
load history due to load-induced local plastic deformations. Principally, residual stresses may be relaxed and new local residual stresses may be superimposed during the fatigue life, if stable. This is of great importance especially when designing welded structures for applications under load conditions with variable amplitude.

- The load-induced change or even the stability of the residual stresses during the fatigue life depends strongly on the local material properties. This means that the local material properties are of utmost importance for the residual stress behaviour and its effect. Here, the base material and its transformation behaviour in the weld zone during cooling down in combination with the cooling conditions and the constraint of the weld defines the resulting local properties and therefore the stability of the residual stresses $[20,21]$.

- The stability of the residual stresses also depends on their origin [22, 23]. Residual stresses resulting from thermal processes or from post-weld treatments such as shot peening or HFMI cannot be handled uniformly.

- Only residual stresses that are stable during the lifetime can be interpreted as mean stresses. It must be taken into account that the material properties (i.e. steel grade) have a significant influence on the residual stress effectiveness. Therefore an improved consideration of the residual stress effect necessarily requires a steel grade-related differentiation of the resulting FAT classes.

- It has to be taken into account that in standard welds with relatively sharp notches, the steel grade usually has no significant influence on the resulting FAT class. However, the acceptable upper stresses are extremely dependent on the material strength. It is supposed that residual stresses should not easily be interpreted as an additional load, but as a factor which influences the local material resistance against plastic deformation. This should be considered in an improved evaluation model.

- An enhanced model cannot be reduced by an improper and more or less intuitive consideration of residual stresses (low, moderate, high). Own investigations [20, 21] have demonstrated that even residual stresses with magnitudes below $0.2 \cdot R_{e}$ can have a significant effect on the fatigue strength. So perhaps stress relief annealing may not necessarily lead to neglectable residual stresses.

- The determination of residual stresses in technical components is not a very difficult task and is a standard tool outside the welding community. This allows for an improved design of technical components in many technical fields, especially in the automotive or in the aircraft industry. It should be possible to establish such a modern tool also in the weld design and the corresponding quality control.

\section{Concept idea}

The idea of the concept is to enable the explicit consideration of residual stresses due to different sources (welding, grinding, milling, shot peening, hammer peening, clean blasting, etc.) in the design rules. A precondition for this is the availability of appropriate residual stress determination techniques. It can be ascertained that nowadays several different device concepts for performing non-destructive XRD-measurements are available. The devices are extremely compact and can be used repeatedly even under really rough and difficult environments. Alternatively, many other methods and devices allow reliable residual stress measurements. Thus, the precondition for a reliable tool for quality control in practice without any specific limitations is basically given.

As the experiences published in different references [20, $21,24,25]$ evidently show, the initial residual stresses are obviously of minor importance. Finally, only stabilized residual stresses at the critical sites can be used. Therefore, it must be known how the relaxation of residual stresses during loading appears or even when new stable residual stresses are generated by local plastic deformations. To consider stabilized residual stresses two possibilities are conceivable:

- Either a repeated measurement after a representative operating condition must be used to control the effective residual stresses after an early load history

- Or a simple calculation tool should enable the design engineer to consider an approximated reliable residual stress condition

Since the relaxation of residual stresses is directly correlated to the yield strength, the consideration of the material properties is obligatory. This means that it is necessary to implement the steel grade. Furthermore, the local mechanical properties resulting from the welding process-related cooling conditions and defining the local hardness distribution are of major importance.

It is postulated that the mentioned parameters will end up in the definition of a local resistance against fatigue cracking. It can be merged with the particular mean stresses considering the mean stress sensitivity to calculate an effective mean stress that can be used as a reference value in notch stress conceptbased load calculation.

\section{Fundamentals}

In [10], a first analytical approach to consider residual stresses in the calculation of the fatigue strength was published. The idea was to evaluate the residual stresses equivalent to mean stresses establishing an ultimate strength depending sensitivity $m$ according to the mean stress effectiveness $m^{*}$ (Fig. 4), 
where $m^{*}$ is well known as a parameter which is influenced by the ultimate strength but also depends on the kind of material.

The precondition in this model is the fundamentally different character of the residual stresses. While mean stresses are necessarily constant, the residual stresses are a variable parameter that can be reduced during the first or the following cycles. The lower the yield strength, the easier it is for the required plastic deformations to occur. As Fig. 4 schematically shows, in low strength materials, static and cyclic yield strength is rarely higher than the fatigue strength (amplitude). This means that the residual stresses must be more or less completely removed during the first loads, regardless of the initial amount of the reverse stress due to plastic deformations, which necessarily makes them insignificant for the fatigue strength. With increasing ultimate strength, the static and cyclic yield strength arise faster than the fatigue strength leading to a higher stability of the initial residual stresses [10,21].

Under consideration of their variable nature, residual stresses can be used to calculate the fatigue strength $R_{A}{ }^{\mathrm{ES}}$ of a material containing residual stress, such as the mean stress affected fatigue strength $\mathrm{R}_{\mathrm{A}}$

$$
R_{A}=R_{W}-m^{*} \cdot \sigma_{m} \quad \rightarrow \quad R_{A}^{\mathrm{RS}}=R_{W}^{\mathrm{RS}=0}-m \cdot \sigma^{\mathrm{RS}}
$$

by using the residual stress sensitivity $m$. Here, $R_{W}$ represents the fatigue strength amplitude under reversed loading and the suffix RS $=0$ stands for a residual stress-free reference value. By using the residual stress effectiveness $m$, the initial residual stresses can be used in the calculation and $m$ is used as a weight factor evaluating the expected residual stress relaxation. The available m-values included in Fig. 5 have been determined in experiments with differently heat-treated and surface-finished steels but the correlation with the ultimate strength is generally reasonable. The assumption in [10] that $\mathrm{m}$ may reach a limit of approximately 0.4 as shown in Fig. 5 has no physical reason, but may be explained with a limited amount of the generated residual stresses due to some technical limitations, as it has not been possible to generate residual stresses close to the yield strength in hardened steels by means of usual technical treatments like grinding and peening. Then

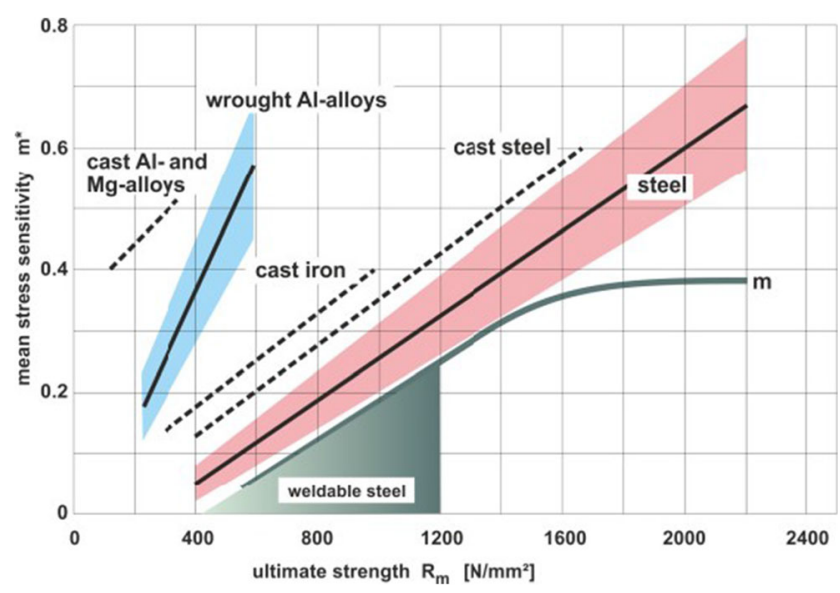

Fig. 5 Mean stress effectiveness factors $m^{*}$ of different metals [26] and residual stress effectiveness in heat-treated steels [10]

a relaxation must not necessarily occur during loading. Pursuing consequently this approach would lead to the combination of both residual stress and mean stress effects in the adjusted form

$R_{A}^{\mathrm{RS}}=R_{W}^{\mathrm{RS}=0}-\left(m^{*} \sigma_{m}+m \cdot \sigma^{\mathrm{RS}}\right)$

or

$R_{A}^{\mathrm{RS}}=R_{W}^{\mathrm{RS}=0}-m^{*} \cdot\left[\sigma_{m}+\sigma^{\mathrm{RS}}\right]$

where residual stresses are handled as mean stresses as correspondingly applied in $[1,7,9,24]$. However, it is not really surprising that both equations cannot be reasonable, since this leads to a strong overestimation of the residual stress effect. In addition, the lack of matching reliable $m$-values for welded materials and weld types may be a reasonable explanation.

\section{Proposed enhanced approach}

The weak point in the $m$-concept is that it generally assumes residual stresses high enough that a relaxation may occur during loading. However, it is uncertain how reasonable it is to
Fig. 4 Interaction of residual stress stability and material strength and consequences for the fatigue strength [10]

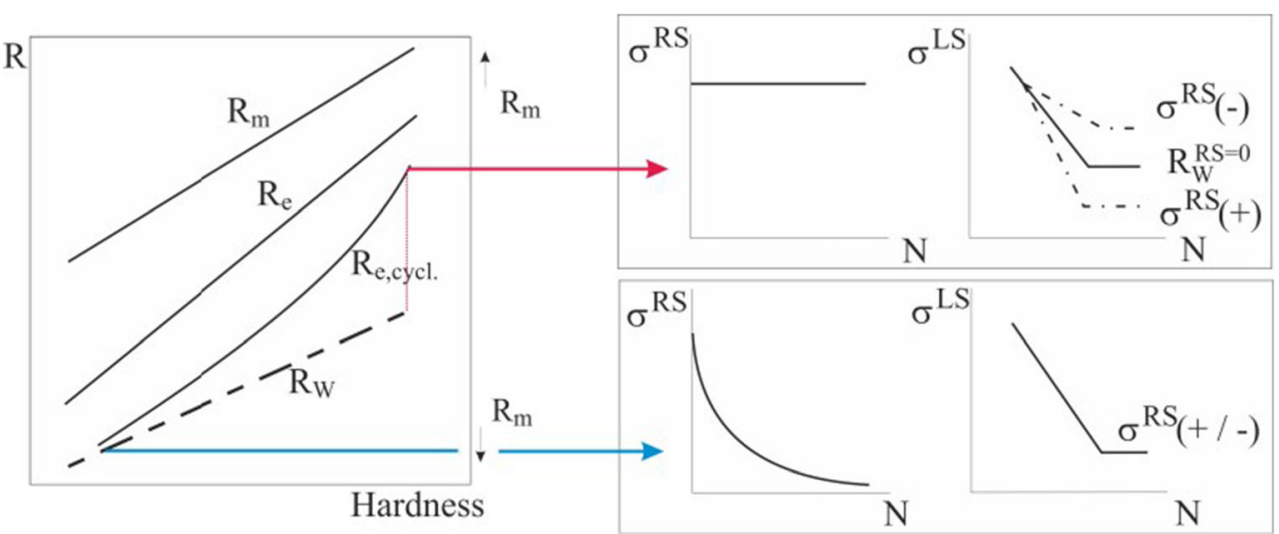


use the same $m$ in cases of lower residual stresses without any significant load-induced relaxation. The question about a possible lower threshold, where the influence of the residual stresses can be neglected, cannot be answered so far, as well as the question about a higher effectiveness of low residual stresses. Finally, an evaluation of the residual stresses such as mean stresses can only be approved in case of a stable condition. This could be possible in the form

$R_{A}^{\mathrm{RS}}=R_{W}^{\mathrm{RS}=0}-m^{*} \cdot \sigma_{m, \text { effective }} \quad$ with $\quad \sigma_{m, \text { fffective }}=\left[\sigma_{m}+\sigma_{N=10^{4}}^{\mathrm{RS}}\right]$

Here, an effective mean stress $\sigma_{m \text {,effective }}$ is introduced, which summarizes the mean stress represented by the load and the "stable" residual stresses [20,21]. Stable means that the residual stresses are almost constant during the whole lifetime until the defined limit is reached. Here, the residual stresses after a relatively short interval of $10^{4}$ cycles are used as a proxy, which is at least not only an arbitrary choice. The experiences in $[20,21]$ and in other publications have shown that under constant amplitude loading without random overloads the residual stress relaxation occurs predominantly during the first $10^{3}$ cycles. Thus, under this load condition, the residual stresses will be certainly stable after $10^{4}$ cycles and this lifetime is short in comparison to the design endurance. Under the described conditions, it is acceptable to evaluate the residual stresses at the estimated failure site as a local mean stress, equivalent to the load stresses. In the case of variable amplitude loading, for instance with occasional overloads, the initial residual stresses will be reduced proportionally to the amount of exceeding the yield strength (load and initial residual stress) when they appear $[11,25]$. Then further cyclic relaxation is unlikely and there is no reason why the residual stresses should be handled not in the same way as under constant amplitude loading.

Many investigations related to the described subject tried to clarify the role of residual stresses $[8,12,13,16,17,24,25$, $27]$ in different weld types. The problem with almost all of these investigations was that either the residual stresses at the crack initiation sites could not be determined precisely or were replaced by assumptive residual stress that was assigned partially opposite to the measured ones [24, 28]. In most of the cases, only relatively low initial residual stresses were finally found and it was assumed a minor importance for the particular results $[14,15,17]$. In [21], comprehensive experiments with fillet welded longitudinal stiffeners of a conventional and a high strength structural steel were carried out under careful control of the initial and load-induced residual stress conditions. Stress relieved conditions after annealing and preloading with loads close to the particular base metal yield strength were used as comparative conditions. Establishing the described effective mean stress shows the systematic correlation of the fatigue strength (stress amplitude) and the effective mean stress built by the mean stresses and the stable residual stresses in load direction (Fig. 6).

The remarkable feature is that the welds of both steels show a decreasing fatigue strength with arising effective mean stress but especially in the compressive range the fatigue strength of the high strength steel welds increase much stronger. In both cases, stress relief annealing leads to a slight effectiveness of the mean stress. The greatest effect can be observed after a pre-loading with a tensile load corresponding to the yield strength of the base metal. Finally, the tendency of the correlation between fatigue strength/effective mean stress can be described uniformly, obviously independent from the steel grade (Fig. 7).

Using the effective mean stresses, a corresponding effective $R$-ratio $R_{\text {eff }}$ was defined. The distribution of the fatigue strength shows an almost horizontal tendency and that is to say a mean stress independence at $R$-ratios $>0.5$. Above $R_{\text {effective }}=0.5 \mathrm{~m}^{*}$ is obviously 0 and that means that higher stress ratios will not reduce the endurable amplitude significantly. Between -1 and $0.5 \mathrm{~m}^{*}, R_{\text {eff }}$ becomes approximately 0.2 , which agrees with the IIW-recommendations and other design rules. In the compressive mean stress range, the effect of the mean stress becomes highly significant, while $m^{*}$ is about 0.4 which indicates that a shift of the effective mean stress in the compressive range has a remarkable higher influence on the fatigue strength than tensile effective mean stresses.

However, the influence of the steel grade is obvious, as shown in [21] In each sample series with longitudinal fillet welds, a particular residual stress condition was found. In the low grade steel, a maximum of the RS was found near the weld toe notch of about $50 \%$ of the base metal yield strength. Nevertheless, the RS could be strongly reduced by annealing and by pre-loading with a tensile overload. The initial RS in the high strength steel was found to be lower than $20 \%$ of the yield strength. Opposite to the low strength steel, an overload generated compressive RS at the weld toe of the high strength steel. Therefore, the fatigue strength-effective mean stress correlation includes also the different amount of the local residual stresses that are affecting the effective mean stress and the resulting effective strass ratio (Fig. 7).

In Fig. 8, the corresponding data obtained in experiments with butt-welded steels in the same strength range are summarized [21]. Here, the experiments were carried out not using constant R-ratios but constant mean stresses. In the Haighdiagrams, the stress amplitudes were calculated from the corresponding SN-curves for $N=2 \times 10^{6}$ cycles and $97.5 \%$ endurance probability (i.e. FAT classes). It can be seen that the low strength steel shows a mean stress effect that is more or less constant over the investigated range. The high strength steels S690Q and S890Q show a tendency similar to that observed in the samples with longitudinal stiffeners. Above 
Fig. 6 Initial residual stresses and after $10^{4}$ load cycles at different stress ratios and result fatigue strength effective mean stress correlation [Hen17]

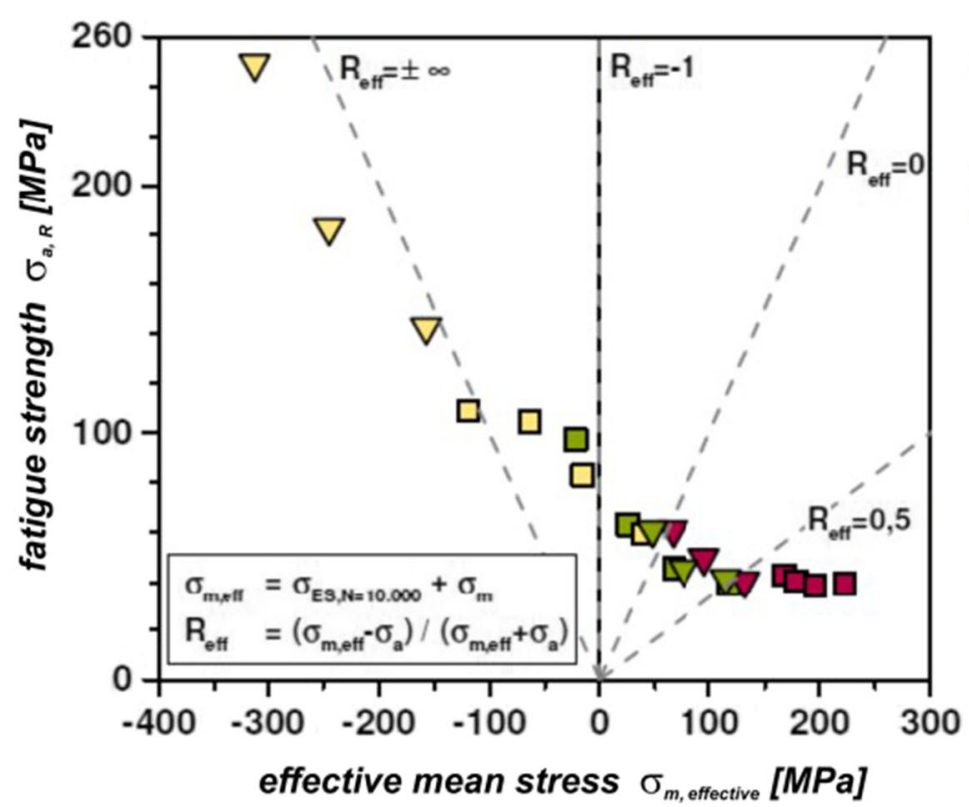

S355NL as-welded

․ S355NL stress relieved

․ S355NL prer-loaded

$\nabla$ S960QL as-welded

$\nabla$ S960QL stress relieved

$\nabla$ S960QL pre-loadeded

\begin{tabular}{|c|c|c|c|}
\hline \multicolumn{4}{|c|}{ S355NL } \\
\hline condition & $R=-3$ & $R=-1$ & $R=0$ \\
\hline $\begin{array}{c}\text { as welded } \\
\text { stress relief annealed } \\
\text { pre-loaded }\end{array}$ & $\begin{array}{l}200 \mathrm{MPa} / 189 \mathrm{MPa} \\
30 \mathrm{MPa} / 26 \mathrm{MPa} \\
-20 \mathrm{MPa} /-11 \mathrm{MPa}\end{array}$ & $\begin{array}{l}200 \mathrm{MPa} / 179 \mathrm{MPa} \\
30 \mathrm{MPa} / 25 \mathrm{MPa} \\
-20 \mathrm{MPa} /-15 \mathrm{MPa}\end{array}$ & $\begin{array}{l}200 \mathrm{MPa} / 158 \mathrm{MPa} \\
30 \mathrm{MPa} / 22 \mathrm{MPa} \\
-20 \mathrm{MPa} /-20 \mathrm{MPa}\end{array}$ \\
\hline \multicolumn{4}{|c|}{ S960QL } \\
\hline condition & $R=-3$ & $R=-1$ & $R=0$ \\
\hline $\begin{array}{c}\text { as welded } \\
\text { stress relief annealed } \\
\text { pre-loaded }\end{array}$ & $\begin{array}{c}100 \mathrm{MPa} / 97 \mathrm{MPa} \\
80 \mathrm{MPa} / 78 \mathrm{MPa} \\
-300 \mathrm{MPa} / \text {-187 MPa }\end{array}$ & $\begin{array}{c}100 \mathrm{MPa} / 95 \mathrm{MPa} \\
80 \mathrm{MPa} / 76 \mathrm{MPa} \\
-300 \mathrm{MPa} / \text {-245 MPa }\end{array}$ & $\begin{array}{c}100 \mathrm{MPa} / 92 \mathrm{MPa} \\
80 \mathrm{MPa} / 73 \mathrm{MPa} \\
-300 \mathrm{MPa} /-300 \mathrm{MPa}\end{array}$ \\
\hline
\end{tabular}

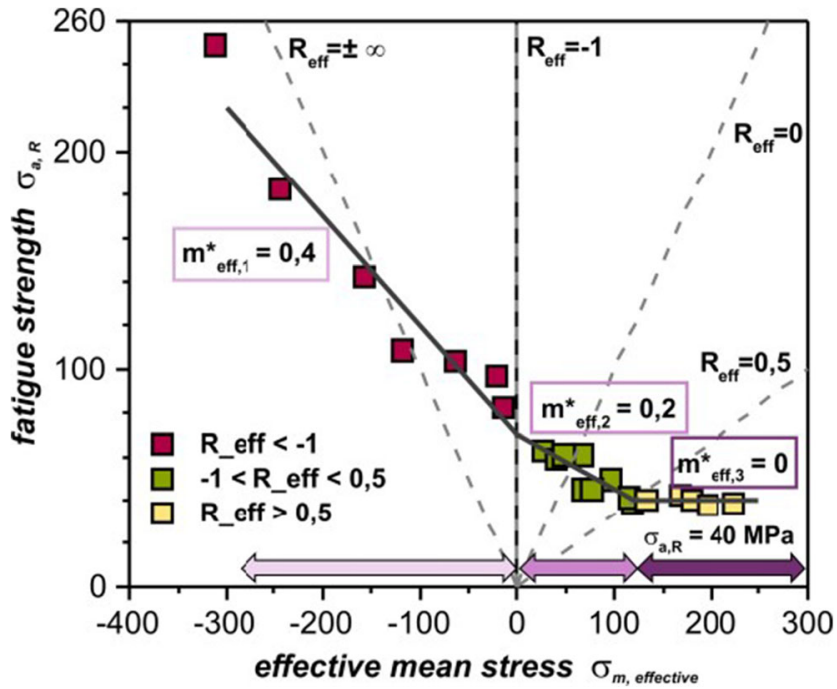

Fig. 7 Effective mean stress relevance for the fatigue strength of fillet welded longitudinal stiffeners [Hen17] a resulting $R$-ratio of 0.5 , the mean stress dependency disappears and under compressive mean the fatigue strength increases significantly.

In this work, it could evidently be shown that the residual stress effect, as known from the material context, naturally depends on the material properties. Here, not simply the material strength can be used as the characterizing parameter, but rather the local properties resulting from the interaction of the material composition and the welding procedure as a function of the cooling conditions and the resulting phase composition. Looking back on Fig. 5, we cannot expect a high influence of the residual stresses in welds under consideration of the strength range where weldable steels are found. However, taking into account the local hardening at the weld toe, a higher residual stress effectiveness is possible even with these materials. Consequently, the effectiveness resulting from the local strength is decisive for the evaluation of residual stresses. An approximation given in [20] could demonstrate that the effective residual stresses assessed by the local hardness depending effectiveness enabled a precise evaluation of the 

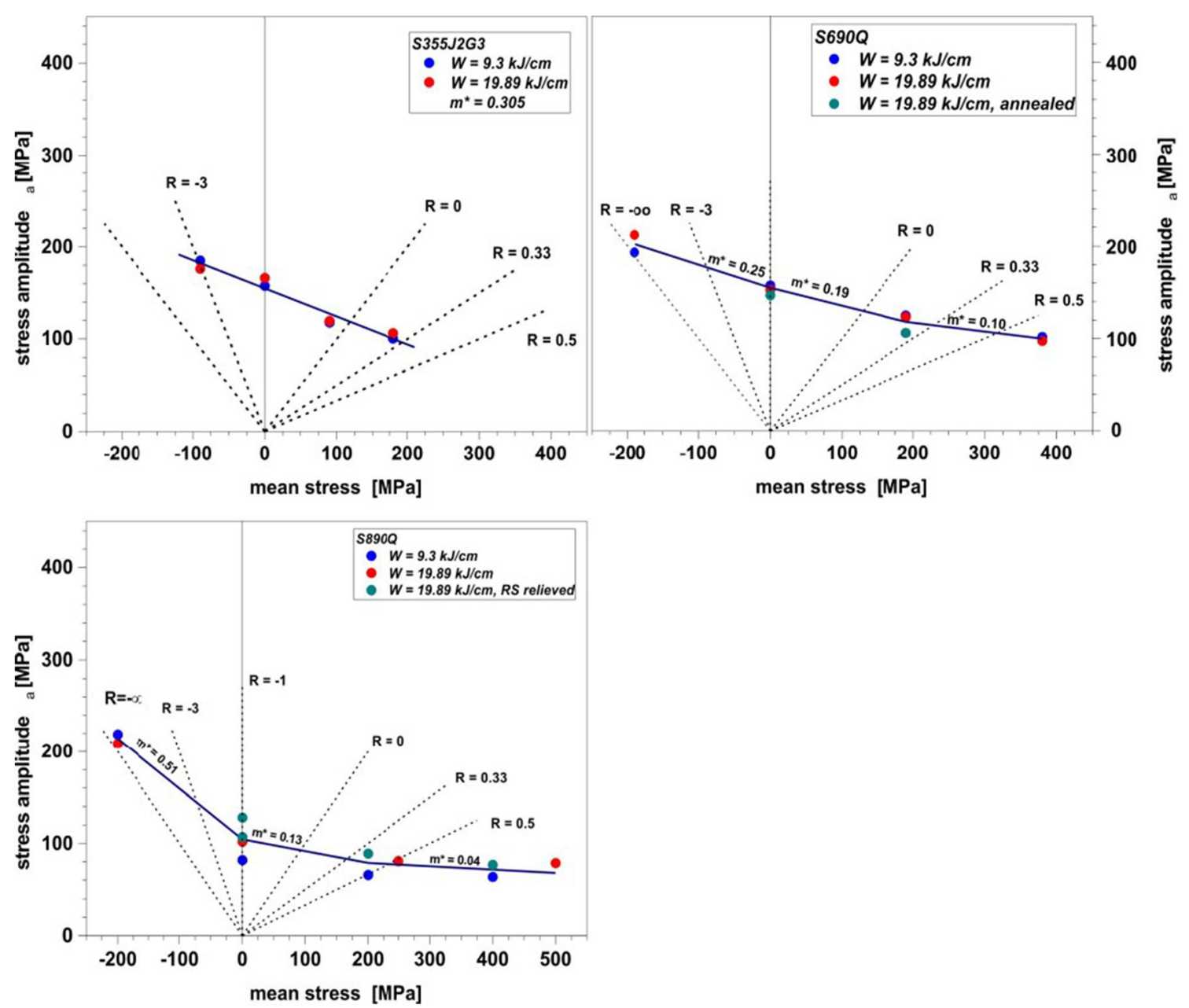

Fig. 8 Fatigue strength-mean stress interaction of butt-welded joints of different structural steels [21]

observed differences in fatigue strength. Finally, it is not the residual stress effectiveness in combination with the initial residual stresses that leads to an applicable solution, but the use of the stabilized residual stresses. Then the RS could be handled as mean stresses using mean stress effectiveness $m^{*}$.

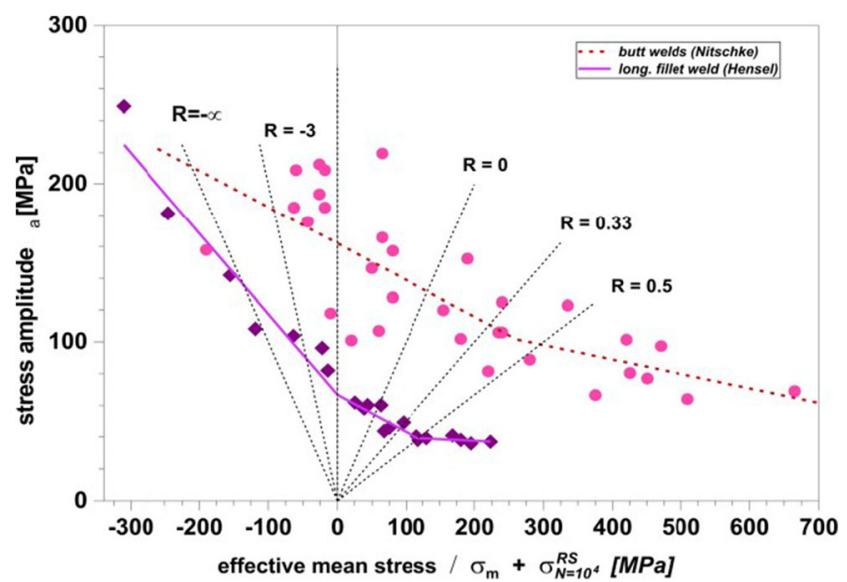

Fig. 9 Modified Haigh diagram considering fatigue test results from different welds establishing an effective mean stress
As Fig.9 shows, using an effective mean stress composed by the load stress and the stabilized residual stresses might enable a plausible evaluation of the combined mean stress and residual stress effect on the fatigue strength of different weld types. The clear mean stress influence on the fatigue strength is obvious for stress ratios below $R=0.5$. Above $R=0.5$, the acceptable amplitude is independent of the stress ratio and the present residual stresses. Here, the upper stress is independent from the material very close to the ultimate strength and that is to say the fatigue strength is presented by the upper stress. More interesting is the range of effective mean stresses, which are compressive. Here, the effectiveness and the resulting amplitude is strongly influenced by small differences in the effective mean stress, and the effectiveness grows up to approximately $m^{*}=0.4$.

This consequently leads to an effective $R$-ratio, $R_{\text {eff, which }}$ uses the effective mean stresses resulting from the mean stresses and the stable residual stresses. In Fig. 10, the presented experimental data with their corresponding bonus factors, which were calculated from the experimental data of butt and longitudinal welds (Fig. 9). Despite the obvious scatter of the 


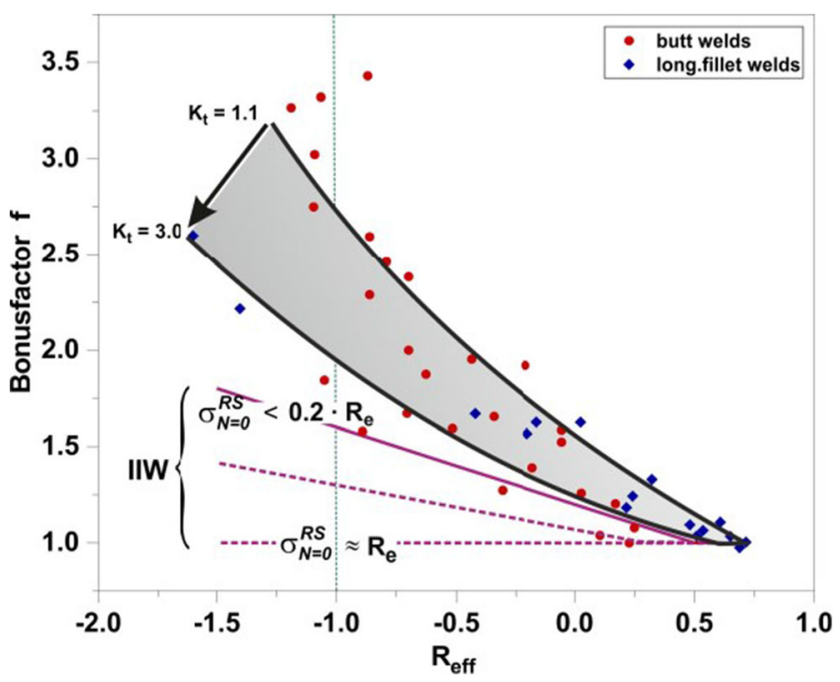

Fig. 10 First draft of a possible modification of the b Bonus-factorconcept under consideration of a residual stress-based effective $R$-ratio $R_{\text {eff }}$

evaluated data, the illustration shows that the combined consideration of mean stresses and the real stable residual stresses matches almost sufficiently with the simple assumptions of the current bonus factor concept. However, with lower tensile or even compressive mean and/or residual stresses a strong discrepancy between the recommended bonus factors respectively mean stress effect grows up. Whether the effect of different notch factors has really the influence like supposed in the illustrated must be discussed further. Nevertheless, the used results of the used comprehensive data show that, in comparison to the existing recommendations, there is a high potential to extend the acceptable loads in cases, when the residual stresses at critical sites in a fatigue-loaded weld are explicitly known.

Especially the higher discrepancies in the range of effective $R$-ratios, below -1 evidently show that an improved consideration of the present residual stresses may offer a high potential for an improved fatigue design in cases where compressive mean stresses and/or residual stresses can be guaranteed. This is probably the case after mechanical surface treatments such as shot peening or HFMI-treatments, for which a large and carefully determined database is currently available ([11] and the referenced literature gives a large overview). As shown in [20], pre-loads can also be very effective, depending on steel grade, its phase structure in the weld toe region and the notch sharpness.

\section{Final remarks}

It should be carefully considered that the weak point (from practical view) of the approach is that the application of this concept unavoidably needs a sophisticated knowledge about the material and the mechanical conditions at the expected crack initiation sites. This includes the following:

1.) The local notch geometry and the resulting notch factor

- This is state of the art. Wide database and well-developed tools for the calculation of the notch stresses with local approaches are available.

2.) The local phase composition

- Using high strength steels necessarily requires detailed knowledge about the composition and the properties of the material. A careful and detailed control of the welding procedures and correlated parameters is mandatory and not a real cost factor (state of the art in companies processing high strength steels). Then easy applicable tools generally allow a reliable determination of the local phase structure and resulting properties $\left(\mathrm{t}_{8 / 5}\right.$-concept, Weldware, JMatPro, etc.).

3.) Detection of service-induced residual stress affecting overloads

- Useful for new constructions. Monitoring and control techniques applicable under difficult environmental conditions are state of the art.

\section{4.) Knowledge of the stabilized residual stresses}

- Applied by (repeated) experimental control. This can be realized using currently available experimental equipment, which allows the determination of near surface residual stresses quickly and also under difficult local conditions. The method is reliable, the application finally a question which can be answered by pondering the effort and the costs and the safety requirements of the component.

- Approximation of stabilized residual stresses with help of load assumptions (may be overloads). This is finally the existing concept and therefore the conservative lower bound of such a concept.

Of course, a practical use of this approach requires further detailed investigations using different weld types, but always considering the effective residual stresses. Then it might be possible to overcome the strong limitations of the conservative and finally unsafe current bonus factor-concept and establish an enhanced supplement which can be used by anyone who tries to use high strength materials in combination with higher quality standards.

It is mandatory and can be expected that the safety of such a concept should be improved continuously by consideration of 
the existing and the coming extended database. It offers a distinguished use of high strength steels and a design that is more and more orientated on the features of modern steels and treatment methods. On the other hand, the engineer keeps the possibility to use the established conservative procedures, if the additional effort is not profitable. Further work to enhance the safety of the concept as well as the universal applicability is of course required.

Funding Open Access funding enabled and organized by Projekt DEAL.

Open Access This article is licensed under a Creative Commons Attribution 4.0 International License, which permits use, sharing, adaptation, distribution and reproduction in any medium or format, as long as you give appropriate credit to the original author(s) and the source, provide a link to the Creative Commons licence, and indicate if changes were made. The images or other third party material in this article are included in the article's Creative Commons licence, unless indicated otherwise in a credit line to the material. If material is not included in the article's Creative Commons licence and your intended use is not permitted by statutory regulation or exceeds the permitted use, you will need to obtain permission directly from the copyright holder. To view a copy of this licence, visit http://creativecommons.org/licenses/by/4.0/.

\section{References}

1. Hobbacher AF (2016) IIW recommendations for fatigue Design of Welded Joints and Components, 2nd edn, IIW document IIW2259-15

2. BS 7608: 2015+A1:2015: Guide to fatigue design and assessment of steel products. BSI Standards Limited 2015

3. Eurocode 3, Bemessung und Konstruktion von Stahlbauten. Teil DIN1993-1-: Ermüdung Beuth-Verlag 2005 +A1:2009

4. DASt-Richtlinie 009: Stahlsortenauswahl für geschweißte Stahlbauten. Deutscher Ausschuss für Stahlbau DAStVerlag: Stahlbau Verlag 2008

5. R.Rennert: FKM-Richtlinie: Rechnerischer Festigkeitsnachweis: für Maschinenbauteile aus Stahl, Eisenguss- und Aluminiumwerkstoffen. VDMA-Verlag 2012

6. DIN-EN 13001-3-1. Krane - Konstruktion allgemein - Teil 3-1: Grenzzustände und Sicherheitsnachweis von Stahltragwerken. Beuth-Verlag, 2012

7. Gurney TR Fatigue of welded structures, $1^{\text {st }}$ edition (1973). Cambridge University Press, Cambridge

8. Fisher JW, Frank KH, Hirt MA (1970) Effect of Weldments on the fatigue strength of steel Beams. National Cooperative Highway Research Program Report 102; Lehigh University, Bethlehem, Pennsylvania USA

9. Haibach E (1989) Betriebsfestigkeit. VDI-Verlag Düsseldorf

10. Macherauch E, Wohlfahrt H Schweißeigenspannungen, Enstehung-Berechnung-Bewertung. In: "Eigenspannungen", Band 1, Hrsg. E.Macherauch und V.Hauk, DGM-Verlag Oberursel 1983, S.85-116

11. Nykänen T, Björk T (2016) JÖRK: A new proposal for assessment of the fatigue strength of steel buttwelded joints improved by peening (HFMI) under constant amplitude tensile loading. Fatigue Fract Engng Mater Struct 39:566-582 2015 Wiley Publishing Ltd

12. Maddox SJ (1982) Influence of tensile residual stresses on the fatigue behaviour of welded joints in steel. In Residual Stress Effects in Fatigue. ASTM STP 776, American society of testing and materials, Philadelphia, S.63-96

13. Harrison JD (1981) The effect of residual stresses on fatigue behaviour. In: Residual Stresses and their Effects. The Welding Institute, p S.9-16

14. Berge S, Eide O (1982) Residual stress and stress interaction in fatigue testing of welded joints. ASTM STP 776, p S.115-131

15. Overbeeke JL, de Back J (1983) The effect of residual stresses and R-value on the service life of welded connections subject to fatigue. IIW-Doc. XIII-1095-83

16. Reemsnyder HS (1981) Evaluating the effect of residual stresses on notched fatigue resistance. In: Materials Experimentation and Design in Fatigue. Proc. of Fatigue '81, Westbury Press Guildford, England, p S.273-295

17. Mang F, Bucak Ö, Steidl G (1984) The influence of residual stresses on the fatigue strength of hollow section joints. Versuchsanstalt für Stahl, Holz und Steine TU Karlsruhe. IIW-Doc. XIII-1122-84

18. Marquis G. B., Barsoum Z., "IIW recommendations for the HFMI treatment - for improving the fatigue strength of welded joints", (2016)

19. Leitner M, Gerstbrein S, Ottersböck MJ, Stoschka M (2015) Fatigue strength of HFMI-treated high-strength steel joints under constant and variable amplitude block loading. Procedia Engineering 101:251-258

20. Hensel J (2017) Einfluß von Schweißeigenspannungen auf den Schwingfestigkeitsnachweis von Schweißverbindungen im Nennspannungskonzept. Dissertation TU Braunschweig

21. Nitschke-Pagel, th.: Eigenspannungen und Schwingfestigkeitsverhalten geschweißter Feinkornbaustähle. Dissertation TU Braunschweig, 1995

22. Vöhringer O (1983) Abbau von Eigenspannungen. In: "Eigenspannungen", Band 1, Hrsg. E.Macherauch und V.Hauk, DGM-Verlag Oberursel, p S.49-83

23. Schulze V (2006) Modern mechanical surface treatment. Wiley $\mathrm{VCH}$, Weinheim

24. Sonsino CM, Kaufmann H, Wagener R, Fischer C, Eufinger J (2011) Interpretation of overload effects under Spectrum loading of welded high-strength steel joints. Welding in the World 55(11/ 12):66/78

25. Siegele D, Baumgartner J, Varfolomeev I, Moroz S, Brand M, Bruder T (2013) Heft 3, Seite) Lebensdauerbewertung von Schweißverbindungen unter besonderer Berücksichtigung von Eigenspannungen. Schweißen und Schneiden Band 65:128-135

26. Schütz W (1967) Über eine Beziehung zwischen der Lebensdauer bei konstanter und bei veränderlicher Beanspruchungsamplitude und ihre Anwendbarkeit auf die Bemessung von Flugzeugbauteilen. Zeitschrift für Flugwissenschaft 15:407-419

27. Fisher JW, Albrecht PA, Yen BT (1974) Fatigue strength of steel beams with welded stiffeners and attachments. National Cooperative Highway Research Program Report 147; Lehigh University, Bethlehem, Pennsylvania USA

28. Kaufmann H, Sonsino CM, Demofonti G, Riscifuli S (2008) Highstrength steels in welded state for light-weight constructions under high and variable stress peaks. Steel Research Int 79(5):382-389

Publisher's note Springer Nature remains neutral with regard to jurisdictional claims in published maps and institutional affiliations. 